\title{
Writing and Vampiric Contagion in Dracula
}

\author{
Erik Butler
}

Bram Stoker's Dracula sums up, within the space of a few hundred pages, diffuse fears and tensions of the society in which it originated. Jonathan Harker, the valiant English foil to the diabolical Transylvanian Count, describes the events he witnesses as "nineteenth century up-to-date with a vengeance" (67). Following this interpretive lead provided by the novel, recent criticism has fleshed out the historical backdrop for Dracula and shown how the novel reflects the emergence of consumerist mass culture (Wicke), the rise of a professional class (Day), and the broad-scale mobilization of electrically-driven forms of communication (WinthropYoung). Stoker's work remains timely more than one hundred years after its initial publication because its eponymous antihero draws his substance and strength as a monster from anxieties and uncertainties that material transformations in the conditions of everyday life produce. Simply replace colonialism with globalization, ministries with multinationals, and telegraphy with the internet: the Count continues to offer an allegory for economic, bureaucratic, and technological changes in the world.

Dracula renews its modernity by means of artful ambiguity in which the up-todate and the out-of-date converge. This essay seeks to demonstrate how modern writing practices and recording technologies act as the gateway through which

Erik Butler is a Mellon Fellow and Visiting Assistant Professor of German at Swarthmore College, where he teaches literature and film. He has completed a book-length study of vampires and post-Enlightenment mythology in Western Europe. His current research focuses on representations of language as war in 17th century Germany and France. He can be contacted at ebutler1@swarthmore.edu. 
corrosive, archaic forces erupt into the present and threaten the future in Stoker's novel. As Jacques Derrida has stressed, writing operates where a human carrier for information is absent; it therefore acts not just as the bearer of data but as the vehicle of uncertainty and indeterminacy as well. New instances of communication reinforce the timeless connection between the grapheme and disquieting impersonality. Stenography, telegraphy, the typewriter, and the phonograph, although nineteenth-century innovations, serve as pathways to atavistic horror by conjuring up the contagious and unanswerable anonymity that characterizes the undead. Dracula continues to solicit critical attention (especially by deconstructionist and media studies scholars) because it delights in scrambling the sexual, legal, and moral codes by which the socio-cultural order consolidates itself. By throwing established systems into crisis, vampirism exposes their historical contingency. The outbreak of the past in the present signifies the continued existence of primitive barbarism in a seemingly enlightened age. Although the story told in Stoker's novel stresses the Eastern foreignness and antiquity of the vampire, the text itself makes it clear that the monster without a reflection in the mirror in fact represents a horrific side of Western modernity.

The first section of the essay examines the fissures and cracks in the personal writing systems of characters in the novel. Most of the major actors in Dracula keep diaries - a written space in which they define who they are. These books represent a closed communications network based on memory: thoughts translate into words and vice versa, and the balance between them forms an anchor for identity. Dracula relies on a different system of writing, using forged and inauthentic documents in order to set the stage for his predations. This paperwork has no connection to a human soul. Because it mediates between the personal and the impersonal, writing provides the conduit through which vampirism creeps into the English social body. Once graphic germs of alterity have entered into circulation, they cause journals kept by Jonathan Harker and Dr. John Seward to stop serving their intended purpose, and Dracula's diabolical plans begin to materialize.

A second section examines the fate of Mina Harker, the young woman most directly involved in the collection, reproduction, and diffusion of documents pertaining to Dracula and his activities. The very texts that serve to track down the vampire exercise a contaminating and denaturing influence on her, and she stands to become like Dracula in kind. Information about vampires displays vampiric properties because impersonal writing opens the body to infection. Mina loses her footing in the human world and steps into the vampire's element when she pursues her transcription work. Furthermore, the heterogeneous writings that Mina transforms into standardized text usher in an atmosphere of paranoia in which the other characters begin to act in as lawless and reckless a fashion as their undead enemy.

The essay concludes with an examination of Abraham Van Helsing, the mysterious foreigner who steps in to oversee Mina's transcription work. The specialist in occult matters resembles the Count-his supposed adversary-in a disconcerting number of ways. In particular, the Dutchman, like the Transylvanian, uses written communications to control the actions of others. If, in fact, Van Helsing is another vampire, then Evil celebrates a triumph in Stoker's novel. The vampire hunters 
follow the dictates of Dracula's double, and they destroy one monster only to enable another one's triumph. Dracula represents the horrifying prospect of England's citizenry turning into a host of virtual clones. He threatens to level distinctions between his victims and to transform them into spectral beings devoid of life and the particularizing traits of individuality. Yet the vampire need not pursue his victims personally in order to make his presence and influence felt, for the very tools the vampire hunters use to combat the monster in fact undermine the identity and order that they seek to preserve. By the end of Dracula, the vampire hunters have become interchangeable parts in a machine fueled by impersonal writing, and Van Helsing, the Count's spitting image, programs their actions.

\section{Journals}

Dracula begins with an office-worker's wanderings. Jonathan Harker, rejoicing that he is "now a full-blown solicitor," makes his way to Transylvania for what will turn out to be a disastrous transaction (45). There he encounters a way of doing business that jars his bureaucratic English sensibilities so severely that it almost destroys him. Harker's enchantment with the Old World quickly turns into fear of the foreign, and the excitingly strange and new environment reveals a terrifying potential to disrupt his grip on reality.

Guilelessly savoring the local cuisine, Harker makes an entry in his diary: "I had for dinner, or rather supper, a chicken done up some way with red pepper, which was very good" (31). Eating habits and writing habits overlap for the Englishman representing his country and its interests abroad. This convergence reveals the main purpose that keeping a journal serves for Harker. Just as bland appreciation represents the outer limit of Harker's gastronomy, his writing serves no further purpose than to pacify his organism: "I turn to my diary for repose. The habit of entering accurately must help to soothe me" (68). Harker's journal maintains a balance in his mind in the same way that food satisfies his stomach. The diary performs a quasi-organic function in organizing its writer's prosaic sensibilities, and Harker uses it to calm and equilibrate his system.

Unfortunately, Harker cannot maintain a comfortable balance in his life once he has set foot into a foreign environment (especially one like Transylvania), and the journal that he uses as an intellectual and existential pacifier begins to malfunction. Harker's "habit of entering accurately" leads him to record data that he cannot process, and, as a result, his own writing begins to appear in a disturbing new light. Imprisoned in Castle Dracula, Harker observes that "this diary seems horribly like the beginning of the 'Arabian Nights,' for everything has to break off at cockcrow-or like the ghost of Hamlet's father" (61). The Englishman reaches for literary analogies in a dim intuition that the same journal that is intended for "repose" in fact harbors a nightmare. On the one hand, the comparisons that Harker makes between his life and literature enable him to reflect with some degree of success on his predicament: he really stands before a supernatural state of affairs. But on the other hand, the literary references mark the limit of what he can process and understand. Harker, who employs his diary only in order to nourish his simple 
ways - taking its contents as a sign that reality has already been taken stock of and inventoried - cannot fully discern the ominous implications of what he himself has written.

Because the mysterious laws governing life (and death) in Transylvania denature the clerical supports of Harker's sense of self, his grip on reality weakens. The widening gap between what his hand has written and what his mind can process prompts the Englishman to call his sanity into question: "there is but one thing to hope for: that I may not go mad, if, indeed, I be not mad already" (67). Dutiful and habitual journal-keeping does not "soothe" Harker, as he means for it to do: it opens the floodgates of horror. Indeed, Harker experiences his most troubling vision-a visitation from the Brides of Dracula-precisely when he passes out "at a little oak table where in old times possibly some fair lady sat to pen, with much thought and many blushes, her ill-spelt love-letter" (67). The diary intended to produce peace and quiet reactivates an archaic inscription of unfulfilled desire: by writing in his journal, Harker unwittingly sets the stage for incubation.

As he lies there, the Englishman confronts visions that threaten him far more than anything he has yet encountered:

I was not alone .... In the moonlight opposite me were three young women, ladies by their dress and manner .... All three had brilliant white teeth, that shone like pearls against the ruby of their voluptuous lips. There was something about them that made me uneasy, some longing and at the same time some deadly fear. I felt in my heart a wicked, burning desire that they would kiss me with those red lips. (68-69)

As critics have observed (e.g. Craft; Roth; Stevenson; Bentley; Griffin), Harker's terror rests on the forbidden yearning for unmanly passivity_ "a wicked, burning desire" to, be penetrated. "Voluptuous lips" that beckon Harker to join a soft and fluid feminine body reveal "brilliant white teeth" that will invade his body and undermine its masculine stability. "I could feel the soft, shivering touch of the lips on the supersensitive skin of my throat, and the hard dents of two . . teeth .... I closed my eyes in languorous ecstasy ..." (70). The "white sharp teeth" that Harker sees, like the "ill-spelt love-letter" that he imagines, express the rise of primordial forces that he cannot master-forces that will sweep him away and destroy him.

The event is so shocking that Harker tries unsuccessfully to dismiss it as a dream. "I suppose I must have fallen asleep," he tells himself, although he promptly confesses that he "cannot in the least believe it was all sleep" (68). In fact, "it" was his writing. Once Harker has lifted his pen from the page, the words are no longer exclusively his own; they mark a divide between the writer and himself, a fissure in his consciousness. As Harker drifts off into a twilight state, the vampire insinuates itself into his mind in shifting and polymorphous guise, through the crack that writing has opened. Why, one wonders, are there suddenly multiple vampires? Until now, the Count has stood alone. Why are these undead creatures female? In effect, Dracula's Brides (two of whom share his features) are extensions of him, and the impurity of their embrace stems at least in part from its latent homosexual 
charge. Harker's entries in his journal provide a breeding ground for the undead, a medium in which the vampire can mutate and take on unprecedented forms of terror.

Dracula, it seems, is neither entirely masculine nor feminine. His genealogy leads back to a "whirlpool of European races" (59), and he therefore resists classification in terms of the ethnic categories so important to the Victorian mind.' Finally, Dracula embodies class confusion. He joins his guest for none of his meals and seems never to partake of food or drink; the Count has no servants and does not engage in the ostentation his English counterparts would use to signify high birth. Yet his claim to have an ancient and powerful ancestry is clearly legitimate. The Count has enough money to make multiple purchases of English real-estate, and there is only Old Money in Transylvania .... Faced with this curious array of facts, Harker can do little more than try to finish the business he was hired to do and hope that his nerves do not give out.

Though rather obtuse, Harker does have one correct hunch: Dracula "would have made a wonderful solicitor" (63). The library in Castle Dracula consists solely of "such books of reference as the London Directory, the 'Red' and 'Blue' books, Whitaker's Almanack, the Army and Navy Lists, and ... the Law List" (50), and the Count takes a keen interest in learning about all the practical aspects of business that Harker can share with him. Dracula's fascination with the workings of commerce points toward his intimate connection to the written word. He calls the volumes comprising his utilitarian library "good friends" (50) and credits them with teaching him English. "I know your tongue through books," he tells Harker (51).

The Count soon reveals why he prizes his library so. The business books and reference works have taught him not only a foreign language, but also a way to worm his way into "mighty London" in order to "share its life, . . . its death, and all that makes it what it is" (51). He has used his book-friends to devise a plan that the guileless British agent (whom he also calls "my friend" [51]) now translates into action. Through Harker, Dracula sets up an array of property deeds and bank accounts that will allow him to move about on English soil undercover. These written documents provide the material basis for the spread of vampirism abroad and, moreover, furnish the key to understanding Dracula's protean nature. With Harker's unwitting assistance, Dracula forges an identity that, as Gary Day puts it, "is . . . a function of . . documentation rather [than] an expression of individual essence" (87). This shadowy, purely formal identity stands at the center of who and what Dracula is. Even though Stoker's novel later reveals that the Count can transform himself into various animals in order to escape notice, he passes unseen in a more subtle way by deploying a panoply of surrogate selves on paper.

The vampire lays the groundwork for his exploits by means of writing. To pave the way for his campaign of terror, Dracula simply posts a letter to "Hawkins and Harker" (191) and the junior partner of the firm comes running to him as a convenient snack. What is more, once the latter is in Transylvania, the Count needs only to do a little more paperwork in order to make his move to England, where he can harvest the unsuspecting citizenry. Written contact makes physical contact possible. The scene that concludes Harker's stay at Castle Dracula ratifies this fundamental connection between vampirism and writing. When the Count has received 
most of what he needs from Harker and can foresee the Englishman's imminent obsolescence, he demotes the overproud pen-pusher, who arrived in Transylvania exultant that he was no longer a mere "solicitor's clerk" (45), back to a subordinate position:

Last night the Count asked me in the suavest tones to write three letters, one saying that my work here was nearly done, and that I should start for home within a few days, another that I was starting on the next morning from the time of the letter, and the third that I had left the castle ...

Reading between the lines, Harker realizes that he has just written his own death notice: "I know now the span of my life" (73). In a perversion of his professional identity, he has written a carte blanche for the vampire who intends to kill him-or worse. Even though Harker manages to escape, the experience unmans him completely and lands him in a hospital, where he is too weak even to write to his loved ones.

Back in England, at another medical institution, Harker's fateful transaction with Dracula bears poisonous fruit. The novel presents a series of journal entries by the alienist Dr. John Seward, who keeps a phonographic diary. Although he is a man of science, Seward does not have a particularly expansive mind. "The unexpected always happens," he remarks in a more profound moment, "How well Disraeli knew life" (143). The doctor's constitutive dullness makes him ill-equipped even to guess what the bizarre behavior of a man in his care might mean (cf. Greenway).

Seward's patient Renfield has an unconventional diet (insects and arachnids), and he exhibits an unusual interest in tables and charts. As the doctor notes, "Spiders are at present his hobby, and [his] notebook is filling up with small figures" (136). Indeed, Renfield writes even when deprived of pen and paper; Seward observes him "catching flies and eating them, and ... keeping note of his capture by making nail-marks on the edge of the door" (151). Seward labels Renfield his "[z]oophagous patient" (150). A more apt designation, however, might be "graphomaniac patient." The madman's appetites are strange and indirectly evoke Dracula's unusual diet, but the raw data that he obsessively records points directly toward the Count. Renfield's scribbling forms a parallel to the utilitarian library at Castle Dracula in that it is purely informational and consists strictly of numbers and charts.. Furthermore, it mirrors the letters that Dracula dictates to Harker inasmuch as it appears to be one thing-merely the idiosyncratic hobby of a lunatic- - when in fact it provides a concrete indication of the Count's arrival in England and the beginning of his campaign.

Once again, before the English representative of social order lays eyes on an actual vampire, he encounters portentous writing that announces his imminent confrontation with an as-yet faceless evil. Vampiric contagion follows the pathways of two-faced writing in Dracula. Renfield's fevered markings on any available surface (from notebooks to door-posts) directly indicate the vampire's influence, yet they are also illegible. The germ of the undead proves invisible either because it is too obvious or because it is too well concealed. Seward cannot see the writing on the wall because he has sensibilities and habits that correspond neatly 
to Harker's. His organism and his journal fit together in the same way that Harker's digestive tract and writing-hand form a closed circuit: "Cannot eat, cannot rest, so diary instead" (93). When not anesthetizing himself outright with "the modern Morpheus $-\mathrm{C}_{2} \mathrm{HCl}_{3} \mathrm{O}-\mathrm{H}_{2} \mathrm{O}$ !" (136), Seward even uses his journal as a soporific: "this diary has quieted me, and I feel I shall get some sleep tonight" (138). Like Harker, he employs his diary above all as a means to assimilate strange experiences to the categories of the known. The apparatus gives him the comfort of talking to himself without going crazy, but at the same time obscures his ability to discern the signs of spreading danger. The phonograph's needle on the recording cylinder forms a trace whose jagged course points toward Renfield's scribbling and, by extension, to Dracula. But while this clue lies in plain view, the doctor instead enchants himself with his own voice and allows the situation to worsen until it becomes terminal.

\section{Transcription}

Alongside the professional young men who prove so resourceless when confronted with a vampire or the signs of its activity, the novel presents another character who has more insight into the supernatural. Mina Murray, Harker's fiancée (and later wife), is more in touch with the way vampirism works because she collects and processes the strange texts that leave others baffled. However, she buys her knowledge at a price, for to the extent that she comes into contact with the graphic traces of the undead, she herself comes to exhibit vampiric traits.

At the beginning of the novel, Mina inhabits a neat and tidy world. An "assistant schoolmistress" (86), she exercises a traditional, womanly role in Victorian society. Her epistolary communication with her best friend, Lucy Westenra, defines her place in the social order. This exchange forms a more or less closed system, and it therefore reinforces each party's femininity: the young women discuss marriage plans, clothing, social visits, etc., in their correspondence. Moreover, Mina dutifully keeps a diary in which she cultivates a modest private sphere and anchors her identity - "a sort of journal ... I can write in whenever I feel inclined"; this journal, she tells Lucy, is "not intended" for others (86). Mina's every thought concerns how she can "be useful to Jonathan" (86) - a perfect wife to the man she will marry.

At the same time, however, the young woman pursues activities that predispose her to deviate from her place in the house and schoolroom:

I have been practicing shorthand very assiduously .... [A]nd if I can stenograph well enough I can . . . write it out . . on the typewriter, at which also I am practising very hard. [. . . ] I shall try to do what I see lady journalists do: interviewing and writing descriptions and trying to remember conversations. I am told that, with a little patience, one can remember all that goes on or that one hears said during a day. (86)

Mina means only to assist Harker, but her stenography and typewriting make her resemble the "New Woman" which she emphatically states she is not (123). In 
effect, to the extent that she devotes herself to clerical work, Mina invades Harker's space, even if she does not mean to do so. ${ }^{2}$ Her studies in business-writing form the opposite pendant to her modest letters to Lucy and personal journal-keeping.

Mina's side interests go hand in hand with a hunger for information in all its forms. As a result of an "unnatural" level of nosiness not restricted to the womanly sphere of gossip and intrigue, she peeks into Harker's "foreign journal" (216) without permission. Although what Mina finds initially shocks her to the point of agraphia (her diary entry reads: "I hadn't the heart to write last night; that horrible record of Jonathan's upset me so" [216]), her habit of imitating the "lady journalists" provides her with the means to recover rapidly. She resolves to "get [her] typewriter this very hour and begin transcribing" the fantastic contents of the journal (216). Indeed, after she has typed out the Transylvanian diary, Mina begins to collect and transcribe scattered documents in order to substantiate what her husband has written. The young woman includes her own journal, newspaper articles, letters, and other characters' diaries, omitting no scrap of text, however small. In effect, Mina has caught the bug that makes Renfield obsessively write down a never-ending stream of data. This bug opens a connection to Dracula.

Through her secretarial work, Mina shows herself to be perfectly capable of performing a "masculine" role, yet this deviance from a woman's place has a dark side. In a half-waking state, Mina senses Dracula's movements and activities psychically. Mina's status as a medium, like all aspects of her character once she has caught the vampire-virus, is ambiguous and threatening. Van Helsing, the Dutch polymath who steps in to advise the English on the undead, voices the danger posed by Mina's second sight: "If it be that she can, by our hypnotic trance, tell what the Count see and hear, is it not more true that he who have hypnotize her first . . . should, if he will, compel her mind to disclose to him that which she know?" (363). Behind the exterior of a "sweet-faced, dainty-looking girl" (257) lurks the menace that Mina will somehow prove to be an instrument of destruction in the hands of Dracula.

According to the plot of Stoker's novel, Mina receives a visit from Dracula in which he sucks her blood and infuses her with the demon seed directly (322ff.). However, "the Vampire's baptism of blood" (362) is not the main reason why Mina takes on undead traits and, in exchange, develops powers of clairvoyance. Jennifer Wicke argues that the young woman's telepathic abilities represent a transfigured version of the telegraph that characters employ in Stoker's novel (475). The intuition goes in the right direction, but the telegraph provides the wrong point of reference for Mina's powers as a medium, since it is merely one of the many new information technologies in Dracula, and one that Mina herself uses only once (217). Instead, Mina's clairvoyance and partial metamorphosis stem from her move into the Count's sphere of influence when she begins transcribing. Parallel to the text that passes through her hands, animal magnetism courses through her body and soul; supernatural connections double material ones. Even the somewhat obtuse Harker realizes as much when he witnesses his wife speaking in a mesmerized state: "I have heard her use the same tone when reading her shorthand notes" (353). 
The sum total of vampiric data in which Mina immerses herself opens her to the Count's advances. Because the master-text that Mina creates through her typewriting charts Dracula's movements and activities, it allows the vampire hunters to anticipate where the Count will strike next. However, since it permits them to know the future, it also radiates a strange, mantic aura. This uncanny property seemingly "rubs off" on Mina, the person in closest contact with it, and prepares her for Dracula's embraces long before the vampire seeks out her body for physical contact.

Although Mina avoids full-blown transformation into a vampire, her situation comes to resemble that of her less fortunate friend. Lucy's letters to Mina reveal why she is Dracula's first victim on English soil and the first full-blooded vampire outside of Transylvania. "Do you ever try to read your own face in the glass? I do," Miss Westenra writes (88). Lucy is definitely the more self-indulgent of the two women, and her narcissism manifests itself as wanton writing. Separated from Mina, Lucy tells her friend in a letter: "I wish I were with you, dear, sitting by the fire undressing, as we used to sit ..." (88). This desire seems natural enough, given that, as Mina says, Lucy and she are "like sisters" (268), but it also contains sinister undertones insofar as it hints at Lucy's inability to tolerate the distance necessary to maintain a well-defined sense of self. Lucy loves to lose herself in others. At the beginning of Dracula, all the single men are courting her, and she would just as soon not commit to any one of them. She has promised herself to Arthur Holmwood, yet she writes to her friend: "Why can't they let a girl marry three men, or as many as want her, and save all this trouble?" (91). Even when Lucy focuses her sexual energy on her fiancé, she cannot restrain her effusions: "[O]h, Mina, I love him; I love him; I love him! [ . . ] I do not know how I am writing this even to you. I am afraid to stop . . . and I don't want to stop" (88). Through lustful thoughts reinforced by reckless writing, Lucy steps into the same realm of dangerous fantasy where Harker encountered the Brides of Dracula. Her graphorrhea opens the way for the Count's advances.

Before attacking directly, the Count takes advantage of the weak spots already present in his victims' lives. As a result, vampirism effectively spreads from the inside out, manifesting itself in states of nervous agitation and excitability before blossoming into physical change. Dracula himself need not be present in actuality in order to be present in effect. It is enough that the regular circuits of communication between members of society be even slightly destabilized for the vampire to exercise his influence. This occult aspect of the undead spreads through writing because the medium seems deceptively neutral when in fact it is not. Compulsive writing provides the purest symptom of infection. Dracula turns Harker into his graphic pathic. Renfield maniacally records masses of figures on every available surface of the asylum. Finally, the men's graphomania parallels Lucy's promiscuous letters and Mina's obsessive transcription work. No mirror throws back the image of the vampire, but writing reveals the monster's presence in refracted form.

The Count does not cast such a long shadow over England entirely on his own. The vampire hunters' own tools contribute to the way that Dracula comes to represent an ever-larger threat as the novel progresses. Through Mina's composi- 
tion of an ostensibly anti-vampiric master document, reports from anonymous sources take a place alongside the characters' most intimate writings, now transformed into standardized, typed text. The anonymous world of mass print invades characters' lives, and reports that formerly would have seemed utterly localized and trivial portend the spread of the undead and plant the seeds of growing alienation.

Information about vampires in mass-mediated form displays the same properties that personal writing does, with the key difference that it implies even greater terrors. Private writing gradually loses its subjective coloration as Mina transforms it into typewriting, and gray and impersonal newsprint becomes infused with potentially limitless personal significance for characters, who find that the terrors in their private diaries resonate with the unsettling implications contained in stories in public journals. For example, the alarm bells go off when an article from the Westminster Gazette reports that "[d]uring the past two or three days several cases have occurred of young children straying from home or neglecting to return from their playing on the Heath .... [T] he consensus of their excuses is that they had been with a "bloofer lady"" (214). Translated into grown-up, "bloofer" means "beautiful," and the lady in question for those in the know is none other than the late Lucy Westenra. The appearance of vampires in print entails a paranoid mindset among characters: a sign of undead activity can lurk anywhere in the countless publications of the Empire, just as any shadow on English soil can conceal a lifestealing corpse. As a result, the vampire looms larger and larger with each passing day. In the arena of the mass media, all the signs can point to Dracula even when another undead does his dirty work for him. The popular press multiplies the vampire's doubling in deeds and contracts ad infinitum.

Under the spell of the mass media, what is private becomes public, and what is public becomes private. The fact that the slightest piece of information can assume, from one moment to the next, importance of the first order reconfigures the normal avenues of communication between members of different segments of society and, as a result, prompts the vampire hunters to act in uncharacteristic ways. Like the flurry of documents changing hands wildly, the vampire hunters begin to jump from one place to another, and from one social milieu to another. The slightest quirk in writing points to the vampire's anarchic mastery of the situation. For example, when Harker approaches a "decent, intelligent fellow, distinctly a good, reliable ... workman," the information the proletarian provides sends the clerk off on a wild goose chase (300). Meaning to signify "deputy" by the glyph "depite" in a note "written with a carpenter's pencil in a sprawling hand," the well-intentioned workman unwittingly aggravates the growing chaos (302). The note exhibits vampiric properties inasmuch as its phonetic spelling dictates a course of action to Harker that sends him down the wrong track.

The vampire hunters' actions mirror Dracula's lawless hunts for blood throughout the big city. As a result, the traditional constraints of propriety, seemliness, and ethics have no hold on them as they attempt to pinpoint Dracula. They run around tomb-raiding, crumble the Host in order to "sterilize" the earth that the Count sleeps in (338), and engage in housebreaking. This behavior not only mirrors Dracula's actions; it also occurs by exactly the same means. To take a particularly striking 
example, Arthur Holmwood makes a killing off of Lucy's death and inherits a title in her extinguished family line; he then uses this title to violate the law. Now "Lord Godalming" (204), Holmwood proposes that the vampire hunters simply break into Dracula's property in broad daylight: "My title will make it all right with the locksmith, and with any policeman that may come along" (339). Presumably, Holmwood is not carrying certification of his new status around in his pocket, but the title that he has obtained under rather questionable circumstances and which he intends to use to circumvent the rules that govern the rest of society points towards the Count. As the menace of England teeming with a "new order of beings" (343) looms on the horizon, the exchange of writing and documents produces a situation that anticipates the nightmare's materialization into reality.

\section{The Programmer}

The very text that enables the fight against Dracula "vampirizes" the vampire hunters by underwriting lawless actions and pushing Mina, the person in closest contact with it, in the direction of becoming an undead herself. Only Abraham Van Helsing shows no sign of suffering a pernicious influence. This is the case because he is a double of Dracula and effectively a vampire himself. He stands apart from the rest of his cohorts, calls the shots from behind the scenes, manipulates others like puppets on a string, and makes them carry out his will.

Van Helsing is "one of the most advanced scientists of his day" (147). "[A] philosopher and a metaphysician," he also "knows as much about obscure diseases as any one in the world" (147). Indeed, he has so many degrees and areas of expertise that even his former pupil cannot keep track. When Seward fears that Van Helsing, because he comes from abroad, "might not be quite aware of English legal requirements," the Dutchman reminds him of the reach of his expertise: "You forget that I am a lawyer as well as a doctor" (200). Uncannily, Dracula can boast of comparable accomplishments. In his non-English English, Van Helsing reveals the Count's intellectual powers:

[Dracula] was in life a most wonderful man. Soldier, statesman, and alchemistwhich latter was the highest development of the science-knowledge of his time. He had a mighty brain, a learning beyond compare .... [T] here was no branch of knowledge of his time that he did not essay. (342-343)

Both Dracula and Van Helsing are foreigners on English soil, old men, mesmerists in touch with the supernatural world, and "mighty brains with learning beyond compare." These similarities between the two antagonists correspond to an even deeper connection that is not readily apparent, but for this same reason even more profound. Dracula does not show its eponymous villain in action nearly as much as one might expect. The Count is a shape-shifting creature who materializes only when closing in for the kill; his potential for destruction is based on his ability to conceal his whereabouts and activities until it is time to strike. As we have seen, the concealing powers of ghostwritten, pseudonymous, or anonymous writing enable Dracula's protean nature and shadowy moves. On this point, too, Van Helsing 
resembles the Count. He has a surfeit of titles: "M.D., D.PH., D.LIT. ETC., ETC." (148), and the fact that he comes from abroad puts it entirely outside the realm of possibility for anyone to check up on his references. Van Helsing can say, do, and command what he wants, and the panoply of degrees lends his wishes and whims logical substance and force in the eyes of the English.

Van Helsing does not step onto the stage of the novel in person; instead, he makes his first appearance in Dracula through a cryptic missive:

My good Friend,-

When I have received your letter I am already coming to you. By good fortune I can leave just at once, without wrong to any of those who have trusted me .... Tell your friend that when that time you suck from my wound so swiftly the poison from that knife that our other friend, too nervous, let slip, you did more for him when he wants my aids and you call for them than all his great fortune could do. But it is pleasure added to do for him, your friend; it is to you that I come.... Till then goodbye, my friend John.

VAN HELSING (148)

This letter opens a series of questions that will remain unanswered, but which conjure up the (unreproduced) correspondence that Dracula used to initiate contact with the English. What "wrong" could Van Helsing, simply by leaving when he does, inflict upon "those who have trusted" him? What undisclosed power does he wield? Like Dracula (who calls Harker his "friend" back in Transylvania), Van Helsing seems unduly concerned with underlining the amicable relations between himself and others (especially "friend John"); such emphasis casts a doubt on whether they really should get along or not. Finally, even if Van Helsing writes English so poorly that the precise details are hopelessly obscure, his intimate relationship to Seward goes back to a mysterious incident that looks like a quasivampiric encounter ("that time you suck from my wound ..."). Indeed, the younger man refers to the foreigner as his "master" (154)-precisely the term that Renfield employs when speaking of the Count (193).

Like Dracula, Van Helsing avoids leaving traces of his activities behind. Even though the Dutch doctor hardly leaves the scene after his introduction one-third of the way through the book, he shares the Count's ghostly aspect. Van Helsing makes epistolary contact under the sign of bloodsucking, but then for the most part holds off from taking up a pen; in the rest of the novel, his discourse is for the most part reported in other characters' writings. Significantly, however, his graphic abstention goes along with an increase of influence. The Dutchman's sway over others only gets larger as the amount of written signs he leaves diminishes. The exceptions to this rule confirm the Dutchman's spectral qualities, most strikingly when Van Helsing parasitically claims Seward's phonographic journal for himself. Speaking into the electric diary, Dracula's supposed adversary barks a directive with vampiric echoes: "This to Jonathan Harker" (355). Because Van Helsing does not communicate his wishes to Harker in person, but instead has a machine (and someone else's, at that) do the talking for him, because his English is full of barbarisms, and, finally, because his words are a command, the Dutch vampire hunter's 
speech evokes the Transylvanian Count's dictation to the unlucky clerk earlier in the novel.

The English characters do occasionally remark something disturbing about their foreign companion. However, because the threat posed by Dracula and the tide of disorienting, undead data have unsettled all the habits and conventions that previously provided them with a clear sense of right and wrong, they can at most express discomfort and unease when Van Helsing seems to go too far. "Professor, are you in earnest; or is it some monstrous joke?" Holmwood asks Van Helsing at one point (243). Even though the doctor protests, "I never jest! There is grim purpose in all I do" (166), his ascendancy in the latter half of the novel makes much of what happens appear in a queer light and even seem like a sick joke.

In particular, Van Helsing's sayings and doings with regard to the dead Lucy are appalling, if also, to the detached reader, darkly funny. At her burial, the Dutch doctor erupts into "a regular fit of hysterics" (211)-behavior so out of line with propriety and decorum that it looks like a case of demonic possession. "He laughed till he cried ... and then he cried till he laughed again; and laughed and cried together, just as a woman does" (211). When a shocked Seward demands an explanation, Van Helsing responds:

[I]t was the grim irony of it all—this so lovely lady garlanded with flowers, that looked so fair as life, till one by one we wondered if she were truly dead ...; and that sacred bell going "Toll! Toll! Toll!" so sad and slow; and those holy men, with the white garments of the angel pretending to read books, and yet all the time their eyes never on the page ... (212-213)

While the clergy pretend to read the holy text, Van Helsing reads their actions. He bursts into laughter because he notices that the clerics are busy looking at the sexy corpse instead of focusing on the burial ritual. In addition, Van Helsing knows that "this so lovely lady ... [looks] so fair as life" because the vampire's embrace has lent her a form of perverted immortality. Lucy, who appears to be a "sweet maid" (213) going to eternal rest will in fact return from the grave in order to seek thrills as an undead. As the doctor observes, she is already a "polyandrist" (213) because of the blood transfusions that he ordered during her period of weakness and decline (157).

In describing the scene, Van Helsing makes an interlinguistic pun. The sounds made by the bells of God's church ("Toll! Toll! Toll!"), translated into German, mean "Mad! Mad! Mad!" The doctor mocks the clerics' imposture, the falsehood of appearances, and his companions' willingness to go along with his schemes. As the novel progresses, Van Helsing time after time puts the credulity of the English to the test, and he always has his way. The most striking instance again involves Lucy and comes when she must be laid to rest once more. The vampire hunters break into the undead girl's tomb to make sure that her rest will indeed be eternal. Acting according to Van Helsing's specifications,

Arthur [Holmwood] took the stake and the hammer ... . [He] placed the point over the heart .... Then he struck with all his might. 
The Thing in the coffin writhed; and a hideous, blood-curdling screech came from the opened red lips. The body shook and quivered and twisted in wild contortions; the sharp white teeth champed together till the lips were cut, and the mouth was smeared with blood. But Arthur never faltered. He looked like the figure of Thor as his untrembling arm rose and fell, driving deeper and deeper the mercy-bearing stake ... (254)

"The grim irony of it all" practically leaps off the page. Holmwood, who meant to marry Lucy, kills her. Instead of experiencing sexual union with his bride, he pounds away on her supine body, "driving deeper and deeper" a stake that will seal their separation forever. Lucy's movements in this moment of intimacy evoke the throes of sexual passion, yet she is clearly having no fun. Her bloody lips and wildly contorted body under Holmwood's vigorous thrusts form a terrible parody of a wedding night. Van Helsing cements the irony by reading a missal on the occasion of these belated nuptials to ensure that Holmwood "strike in God's name" in order to consecrate the unseemly and disgusting scene (254).

Although the English in Dracula initially try to keep their sense of the world balanced with their private journals, writing ultimately serves to eliminate selfhood as Van Helsing steps in to take control of the crisis situation that the Count has ushered in and uncanny, impersonal forms of writing have exacerbated. Mina devotes herself so thoroughly to collecting and transcribing data that she almost becomes a vampire. Harker, with a clumsy but complete attention to detail, follows every written lead like a robot. Holmwood employs the title that he has inherited in order to sidestep the law and, in the process, acts more like a common criminal than the Lord that he now is in name.

As the story progresses, Dracula presents more and more scenes in the lunatic asylum, which even becomes the vampire hunters' base of operations. Generalized vampirism also affects the doctor-patient relationship between Seward and Renfield, and Van Helsing's pupil seems almost eager to see the man in his care continue to suffer. Where one might expect at least a small measure of recognition and appreciation for the one individual who has known all along what is really happening in England, we instead witness a coldly mercenary attitude that evokes the Count's calculated cruelty. The practice that constitutes Seward's identity as a physician is denatured as he, in the ghoulish company of the other characters and under the influence of undead writing, exploits another's misfortune in order to get the information that he desires.

Not long after gruesomely dispatching Lucy — an event in which the vampire hunters spectacularly demonstrate their willingness to perform actions they would never have dreamed of previously - the cohorts return to the asylum to catch their breath. Seward finds Renfield "in a state of considerable excitement, but far more rational in his speech and manner" than ever before (282). Speaking to the doctor "as ... an equal" (285), the patient describes the details of his case with all the subtlety of a man of law. Unlike Renfield's earlier discourses, his speech now makes no reference to mysterious visitations from a supernatural being. Rather, it is couched in the jurisprudential and medical terminology familiar to polite society. "I am as sane as at least the majority of men who are in full possession of their 
liberties," the patient concludes (283). In comparison to the way that Harker, Holmwood, et al. have been acting, he certainly has a point.

When the growing threat posed by vampirism has definitively stood the normal order of things - and discourse — on its head, Seward takes a renewed interest in Renfield. For the first time, the doctor engages his patient in conversation. In retrospect, Seward can see that Renfield was the first person in England to perceive the coming tide of horror and to attempt to notify others. Yet, as Geoffrey WinthropYoung notes, "vampire hunters need information as much as Dracula needs blood" (112). By this point in the novel, Seward's new calling as a Ghostbuster has usurped his professional identity as a man of science, and anti-vampiric paperwork has buried the Hippocratic Oath. His interest in Renfield concerns a pathological specimen, not a human being.

The patient wants his doctor to release him from the asylum. Seward feels constrained to restore full civil liberty to Renfield and thereby sacrifice an invaluable source of data. However, Mina has been recording the madman's speech all along, and her transcript offers Seward a way to keep Renfield in his custody. The same words mean one thing when they are spoken, and another when typed. The doctor "smile[s]" as he "[lays his] hand on the type-written matter" (294): Mina's transcript gives him a new perspective on his patient's case. Turning away from Renfield himself, Seward consults the document:

Several points seem to make what the American interviewer calls "a story"....

Here they are:

Will not mention "drinking."

Fears the thought of being burdened with the "soul" of anything.

Has no dread of wanting "life" in the future.

Despises the meaner forms of life altogether, though he dreads being haunted by their souls. (311-312)

The text makes incongruities in the patient's speech, which the doctor overlooked when giving him his undivided attention, leap to the fore. Through the lens of the typewritten transcript, Seward automatically sees Renfield's discourse in a new light. Abstracted from its original, embodied performance and placed on the page, Renfield's eloquent oratory becomes clinical evidence devoid of pathos and power. The facts on the page point one way: "The Count has been to him [Renfield], and there is some new scheme of terror afoot!" (312).

The doctor can finally decode his patient's "delusions." Seward's ruminations in his own journal led him nowhere, but the typewritten text Mina has prepared brings the situation into sharp focus. Needless to say, the new clarity of things has a human price, which Renfield pays. The transcript serves as a surrogate body that substitutes for the patient's suffering, human form. The textual corpus is legible in a way that a living man is not; it is therefore of greater utility to Seward and his cohorts. For this reason, Renfield himself becomes utterly disposable in the eyes of the vampire hunters - merely "a sort of index to the coming and going of the Count" (264). Before long, he meets with "some accident" that is suspiciously opportune for the doctor and his associates (314). Seward and Van Helsing keep him from 
giving up the ghost only long enough to extract from him the information they want. They can be perversely content with an innocent man's demise, since, in passing the frontier between life and death, Renfield gives them the facts they need. Dr. Seward-especially in the presence of his "master"-is as cold-blooded as Dracula.

\section{The Vampire's Triumph}

On the surface, the battle between Dracula and the vampire hunters seems to present the victory of Good over Evil. On a deeper level, however, the moral and metaphysical trappings of Stoker's novel are irrelevant. As Friedrich Kittler observes, the side with the fastest data-relay system wins. An impersonal, instrumental intelligence reestablishes Order under Heaven. This power does not belong to a benevolent and omniscient "Recording Angel" floating above, as the none-toobright Harker assumes (367). Instead, it belongs to an old man down on earth who commands the pious fingers of a young lady and the vigorous limbs of dutiful and compliant young men.

The rustic vampire trying to make it big in London shows himself to be hopelessly out of touch with life in the metropolis and the pace of modernity. He uses the ridiculously parvenu-sounding name "Count de Ville" as an alias (312) and walks the streets wearing a straw hat-an accessory which, in the words of his nemesis, Van Helsing, "suit not him or the time" (357). More importantly, Dracula employs superannuated communications technology. Winthrop-Young observes that Dracula's foray into the foreign meat-market "resembles that of an early modern merchant directly involved in all purchasing ventures" (116). The Count "does not advance beyond hand-written letters" and personal interaction when he goes about his infernal business (115). These old-fashioned methods bring him a certain measure of success. He lures Harker to Transylvania and then uses the clerk's contacts to set up a series of documentary covers for himself. Dracula reproduces numerous missives from Mina to Lucy with the ominous note, "Unopened by her," thereby indicating that the vampire has already taken possession of Miss Westenra. Throughout the novel, the Count also controls the mail. ${ }^{3}$ But although Dracula wins a few initial skirmishes, he simply does not operate quickly enough in the epoch of typewriters and telegrams, nor can his "snail mail" compete with the dataprocessing network which Mina administrates and Van Helsing oversees. Dracula is stuck in the past, or, as Van Helsing contemptuously puts it, "[i]n some faculties of the mind he ... is ... only a child" (343).

In contrast, the vampire hunters employ ultra-modern and fast technologies. And because they operate with reproduced documents, not originals, Dracula does not stand a chance. Mina types out all the data she can gather into easily legible, standardized print and uses "manifold" - in other words, carbon paper (262). When Dracula attempts to foil his enemies by breaking into their base of operations and making "rare hay" (325) of Mina's master-text, the vampire hunters emerge unscathed because they can still avail themselves of another copy they keep in a safe. Finally, Mina's transcript changes hands freely, and the information about vampiric 
activities that it contains is therefore the equal possession of all.

But the writing that serves to trap the vampire itself displays vampiric properties. The characters' own graphic activity betrays them by exposing them to things they are ill-equipped to handle. The opening sequence of Dracula shows how Harker's clerical habits nearly bring about his destruction. Even though he survives, he will never be the same. By the middle of the novel, all the other characters have also undergone a transformation. ${ }^{4}$ The germ of undead alterity corrupting English identity and the social order that underpins it starts with a lying letter postmarked in Transylvania. It quickly transforms itself into a veritable plague of denaturing data flowing freely and wantonly among characters in England. The figures who preside over this preternatural writing-Mina, the quasi-vampire, and the mysterious Van Helsing, the Count's double-highlight how messed-up things have become.

Diaries initially form the material support for individual identity and, by extension, for the social mosaic by reinforcing their users' inherited notions of selfhood and place in the world. However, as the threat of vampirism grows and forces characters to share their personal writings with others, these documents begin to produce effects opposite to the ones for which they are intended. Previously private and closed books turn into impersonal, open text, and their writers' identities start to unravel. Not all characters show the signs of turning into a vampire outright, but they uniformly act in ways disallowed by convention and tradition as they try to fight the foreign invader. Even when the "good guys" are not breaking the law, their actions appear starkly unnatural (e.g., watching a nutty old man put a girl into a trance in order to hear her talk about another crazy foreigner buying up English real estate by day and sucking young women's blood by night). The vampire hunters can only reconstitute themselves by becoming largely interchangeable cogs in a machine that Van Helsing runs. In doing so, they give up the last traces of their individuality.

One character we have passed over until now provides the exception that proves the rule. The vampire hunters include, besides Van Helsing, a second foreign body. Introduced as one of Lucy's suitors early on, the American Quincey Morris, like the best of his countrymen, is a free-spirit and very much his own person. When it becomes clear that he will not have Lucy's hand, he is also a gracious loser. The English characters praise him as a remarkably "nice fellow" (90), and they find his American idiom and the colorful tales he tells charming. Yet what brings Morris to England? No one in Dracula asks this question, but perhaps they should ....

From a Marxian perspective, Franco Moretti argues that Morris is a vampire. Like Dracula, he is a foreigner who represents an economic system inimical to the English social order and his hosts' traditional way of life. Breakneck American capitalism and atavistic Transylvanian feudalism pose equal threats to the stability and well-being of Great Britain. As Moretti observes, the word "vampire" appears in Dracula for the first time when Morris tells his companions about an adventure in South America: "[o]ne of those big bats that they call vampires" drained his horse of its blood in the Pampas (188). Furthermore, Morris acts in a suspicious 
manner at key moments in the vampire hunt. During a session to plan a course of action against the Count, he takes leave of the others in order to shoot at a big bat hanging outside the window and spying on the proceedings. The American misses, Moretti suggests, because he does not intend to kill Dracula at all; instead, he merely wants to provide a smoke-screen for himself. And when the vampire hunters find Dracula physically assaulting Mina, Morris inexplicably runs off and hides "in the shadow of a great yew tree" (323) before returning to tell the others that the Count has escaped. Like a true vampire, the American is fundamentally duplicitous. "So long as things go well for Dracula, Morris acts like an accomplice. As soon as there is a reversal of fortunes, he turns into his staunchest enemy" (Moretti 95). Morris eagerly participates in the hunt for the Count on his native soil, in Transylvania - that is, once the English have gained the upper hand and are on the verge of destroying their adversary. For no apparent reason, the American suffers a mortal blow at the hands of the Count's Gypsy allies just as the vampire hunters catch up with their prey. It is only logical, Moretti argues, that Morris die when Dracula does. The American's sudden and apparently unmotivated death at the last minute "fits perfectly into [the] sociological design" of Stoker's novel (95), which presents the exorcism of forces that are pernicious and destabilizing to the English social body.

However, the final document included in Dracula suggests that a complete purification does not occur. A note from Jonathan Harker's hand concludes the novel:

Seven years ago we all went through the flames; and the happiness of some of us is, we think, well worth the pain endured. It is an added joy to Mina and me that our boy's birthday is the same day as that on which Quincey Morris died. His mother holds, I know, the secret belief that some of our brave friend's spirit has passed into him .... [W] call him Quincey. (419)

On the one hand, the way that things have worked out seems to fall in line with the triumph of life. Seven years after the terror, Dracula has not returned, and the Harkers have added a young member to their family. Their son represents the renewal of full-blooded English stock in years to come. But on the other hand, the new generation also provides a bridge to the troubling past. The young Harker's birth coincides not only with Morris's death, but also with Dracula's. As we have seen throughout this essay, vampires disappear only to reappear later in another form. In the cyclical time of the calendar, the child's entry into the world overlaps with the vampire's vanishing from it. This convergence points toward the possibility that the monster has wormed its way into another body and lies dormant, waiting to strike when least expected. In addition, we have seen in some detail how the undead work under textual and onomastic cover. The child's name is ominous. If in fact "some . . . spirit has passed into" the young Harker, then a horror lies in store. Mina, of all people, should know what it means for a "spirit" to pass from one being to another.

In this light, we can understand why Dracula does not put up much of a fight when his pursuers finally catch up with him, and why, "in [the] moment of final 
dissolution, ... a look of peace" appears in his face (418). The vampire goes to rest secure that he will soon be reborn in a new, and better, disguise. His many reincarnations since the publication of the novel prove his confidence justified. Stoker's work has gone through too many reeditions and adaptations to count. Dracula has appeared in print, on stage, on the radio, on film, and in televised programming. Diffused in the media, the vampire lurks in every home, where each new generation receives him through the bloodstream of mass culture like mother's milk.

\section{Notes}

'Stephen D. Arata argues that Stoker's novel presents a nightmare vision of the races subject to English rule turning the tables on their oppressors. In this context, Dracula appears as a miscegenated Leviathan with European, African, Asian, and American blood. See also Alexandra Warwick's "Vampires and the Empire: Fears and Fictions of the 1890s."

2 Indeed, according to the fiction of Dracula, Mina is the work's author. For insightful discussions of the relationship between gender trouble and narrative control, see Alison Case's "Tasting the Original Apple: Gender and the Struggle for Narrative Authority in Dracula" and Marjorie Howes's "The Mediation of the Feminine: Bisexuality, Homoerotic Desire, and Self-Expression in Bram Stoker's Dracula."

${ }^{3}$ The evidence abounds; e.g., Harker's statement upon finding Dracula's correspondence: "It gave me almost a turn to see again one of the letters which I had seen on the Count's table before I knew of his diabolical plans. Everything had been carefully thought out, and done systematically and with precision" (265).

${ }^{4}$ Harker's accelerated aging is exemplary of his growing likeness in kind to the "pale people" (320): "Harker was still and quiet; but over his face . . came a grey look which deepened and deepened in the morning light, till . . the flesh stood darkly out against the whitening hair" (328); cf. also Seward's remark about Holmwood: "Poor fellow! He looked desperately sad and broken. Even his stalwart manhood seemed to have shrunk ..." (205).

\section{Works Cited}

Arata, Stephen D. "The Occidental Tourist: Dracula and the Anxiety of Reverse Colonization." Victorian Studies 33.4 (1990): 621-645.

Bentley, Christopher F. "The Monster in the Bedroom." Literature and Psychology 22 (1972): 27-34.

Case, Alison. "Tasting the Original Apple: Gender and the Struggle for Narrative Authority in Dracula." Narrative 1.3 (1993): 223-243.

Craft, Christopher. '“'Kiss Me with Those Red Lips': Gender and Inversion in Bram Stoker's Dracula." Representations 8 (1984): 107-133.

Day, Gary. "The State of Dracula: Bureaucracy and the Vampire." Rereading Victorian Fiction. Ed. Alice Jenkins and Juliet John. New York: St. Martin’s Press, 2000. 81-95.

Greenway, John L. "Seward's Folly: Dracula as a Critique of 'Normal Science." Stanford Literature Review 3.2 (1986): 213-230.

Griffin, Gail. "“Your Girls That You All Love Are Mine': Dracula and the Victorian Male Sexual Imagination.” International Journal of Women's Studies 3 (1980): 454-465.

Howes, Marjorie. "The Mediation of the Feminine: Bisexuality, Homoerotic Desire, and Self-Expression in Bram Stoker's Dracula." Texas Studies in Language and Literature 30.1 (1988): 104-119.

Kittler, Friedrich. “Dracula’s Legacy.” Stanford Humanities Review 1 (1989): 143-173. 
Moretti, Franco. "Dialectic of Fear." Signs Taken for Wonders: Essays in the Sociology of Literary Forms. Trans. Susan Fischer et al. London: Verso, 1983. 83-108.

Roth, Phyllis A. "Suddenly Sexual Women in Bram Stoker's Dracula." Literature and Psychology 27.3 (1977): 113-121.

Stevenson, John Allen. "A Vampire in the Mirror: The Sexuality of Dracula." PMLA 103.2 (1988): 139-149.

Stoker, Bram. Dracula. Ed. Glennis Byron. Peterborough, Ont.: Broadview Press, 1998.

Warwick, Alexandra. "Vampires and the Empire: Fears and Fictions of the 1890s." Cultural Politics at the Fin de Siècle. Ed. Sally Ledger and Scott McCracken. Cambridge: Cambridge University Press, 1995. 202-220.

Wicke, Jennifer. "Vampiric Typewriting: Dracula and its Media.” ELH 59 (Summer 1992): 467-493.

Winthrop-Young, Geoffrey. "Undead Networks: Information Processing and Media Boundary Conflicts in Dracula." Literature and Science. Ed. Donald Bruce and Anthony Purdy. Atlanta: Rodopi, 1994. 107-129. 